\title{
PATIENT SAFETY IN THE ASPECT OF PROCESS AND PROCEDURES CONNECTED WITH MEDICAL SERVICES
}

doi: $\quad 10.2478 /$ czoto-2019-0035

Date of submission of the article to the Editor: 20/12/2018

Date of acceptance of the article by the Editor: 19/02/2019

\author{
Aleksandra Zyska ${ }^{1}$ - orcid id: 0000-0002-4823-4776 \\ Igor Grofelnik ${ }^{2}$ \\ ${ }^{1}$ Częstochowa University of Technology, Poland, aleksandra.zyska@wz.pcz.pl \\ ${ }^{2}$ University of Maribor, Slovenia
}

\begin{abstract}
In the paper the risks to which the patient is exposed while receiving a medical service have been analyzed. All treatments related to blood collection from the patient deserve much attention. It consists of a number of principles and procedures regarding the patient's health safety as well as safety of a person providing this service. Prevention and preventive actions in the aspect of patient safety in the face of threats resulting from the nature of medical services provided are a priority. Due to preventive action it is possible to avoid the effects of exposure to biological hazards, including the possibility of becoming infected with HIV, HCV and HBV. In the paper the results of a questionnaire survey carried out in selected blood stations of the Śląskie Voivodeship have been presented. The questionnaire is able to collect the information about patient awareness on the risks of the medical service (blood collection).
\end{abstract}

Keywords: safety management, medical service, biological threats, preventive actions

\section{INTRODUCTION}

Each professional work carries a number of dangerous, arduous and harmful factors. When identifying threats, it is necessary to distinguish between dangerous (or accidental) hazards, physical, biological, chemical and psychophysical hazards. There are some professions that generate most of them. However, whether a given profession belongs to a higher-risk group is determined by exposure to a given factor as well as the probability of effects that have a direct impact on the employee's health and life (Eyles, Manley, Jones 2018).

Health professionals have contact with many factors that can affect their health and life in a negative way. All of them are important, but there are some that should be paid special attention to. The fact that work in the health service carries a number of psychosocial hazards is obvious, although they belong to the group of non-normative threats, often also referred to as "transformational". Their main source are the complex processes of the transformation of the political system that have been 
occurring in Poland for over ten years. The mentioned threats are manifested, among others, descending so-called social support, growing tensions and conflicts, fear of losing employment, low wages. The current image of a health care worker is also gradually changing. A new phenomenon is the American custom of lawyer's law practice, which involves the search for potentially injured patients as a new customers. A separate aspect of psychosocial risks is aggression on the part of patients who often blame health care professionals for their illnesses. According to estimates of The Bureall of Labor Statistics at the end of the 90s of the twentieth century in the USA, an active assault experienced 8.3 per 10 thousand. Medical workers (Idzyniec and Konodyba-Szymański 2019) should also be taken into account, the impact of human resources issues on provision of medical services (RosakSzyrocka, 2018).

The problem of threats from patients and their families begins to be noticed also in Polish healthcare facilities. In addition, the level of stress among medical workers increases, which is associated with an increased risk of errors. It can even occur in routine medical examinations and services. One of the most important threats in the work environment of the health service are biological factors of occupational hazards, which are considered to be the most serious consequences for both medical staff and patients. The main danger remains the possibility of getting infected from the patient or members of his family. Blood-borne infections - HBV and HCV viruses and HIV (Pirozzollo and LeMay 2007) are particularly dangerous and often concealed.

Biological factors of occupational hazard are widely recognized as the most serious health and life threat to healthcare workers (doctors, nurses, auxiliary personnel). The already mentioned blood-borne infections are particularly dangerous. The World Health Organization estimates that, globally, about 40 million medical workers, as many as 3 million people are exposed to skin contact with blood-borne pathogenic organisms. Of this, as many as 2 million people can become infected with the HBV virus, about 1 million with the HCV and about 170 thousand with the HIV. The effects of blood-borne infections in Poland may be demonstrated by a matter from a few years ago regarding the detection of hepatitis in 2 out of 95 physicians and 5 out of 150 nurses working in one of the large hospitals in Lodz during periodic examinations (Irzyniec and Konodyba-Szymański 2010).

Blood-borne infections were intensified in the 80 s of the last century. Indeed, the highest number of infections, for example HCV, has occurred in healthcare facilities. The source was, among other things, blood transfusion to women before childbirth. This resulted in a large number of infected people who are currently 40-50 years old (http://www.rynekzdrowia.pl/Uslugi-medyczne/Trzeba-byc-czujnym-by-nie-zarazic-sieHCV,105875,8.html; Aniszewska et al., 2019). At the present time, as can be read in specialist reports, HCV infections in blood therapy are practically non-existent. The medical facility have worked out in accordance to sanitary procedures, which is why the risk of getting a blood-borne infection has decreased.

Numerous research results show that improper management of an enterprise or failure to follow system procedures can cause a danger at work (Niciejewska and Klimecka-Tatar, 2018). Unfortunately, there are cases resulting from thoughtlessness or lack of awareness that infection occurs during normal blood collection. The case presented in the media, the nurse used disposable needles, syringes, but, for example, did not change the gloves after each patient. Shaping the awareness of a 
safe medical service both among the staff who provides them and the patients who use it is a priority.

These problems are not only found in adult patients. It also affects the youngest patients whose performance of the medical service is difficult (Welch 2019). Work in the health care system also determines the system approach in managing work safety. This safety is perceived from the perspective of both health care professionals and the patient, as both groups of medical service participants are equally exposed to threats resulting from medical services.

Each medical service requires special precautions, especially in the case of contact with body fluids. Blood and its ingredients are irreplaceable and widely used healing agents. In Poland, in the treatment of patients, they are used by over $80 \%$ of hospitals, and about 1.5 million blood units and its components are swallowed annually. Therefore, it is extremely important to ensure a properly functioning system of blood donation and blood therapy. Taking into account the patient's supply of effective and adapted to the current needs. At the same time, this system should guarantee the safety of blood donors and recipients and the optimal use of this priceless medicine.

Demographic changes, emigration of young people, contemporary pace of life and factors affecting the health of the population limit the number of potential blood donors in Poland, which, with the simultaneous development of medicine, poses a risk of insufficient blood supply. As most developing countries are trying to reach $100 \%$ voluntary non-remunerated blood donation by applying WHO standards, in some countries such as United States offering material incentives to recruit blood donors is becoming a common way to meet blood demands (Abolghasemi et al., 2010). Since the acquisition of this medicine (blood) is dependent on the good will of donors, almost exclusively and honorable (Evans and Ferguson, 2014; Misje et al., 2005).

It is necessary to provide blood donors with safe and convenient conditions for its donation. The risks associated with the use of blood and its components, as well as their limited resources, require the creation of effective supervision of both the acquisition, processing and storage as well as the clinical use. Patients should be guaranteed that in cases justified by their health condition, they will immediately receive safe blood (subjected to research, properly prepared and stored), and donors ensure that their gift is properly used (Twaróg and Ojrzyńska, 2018).

Considering that there is a blood donation and healing system, one should focus on an individual approach both to medical staff and patients. The awareness of employees and patients regarding the consequences of failure to comply with safety during the provision of a medical service, especially during blood collection, which is often routine, is a priority. The results presented in the article testify to the great potential for improvement in this matter.

\section{METHODOLOGY OF RESEARCH}

Services need specific methods of rsearch (Ingaldi, Ulewicz, 2018), especially medical services. Therefore in this work the analysis of the literature on the subject, both foreign and native, have been made. To evaluate patients' knowledge of the potential threats with which they have contact during the medical service (blood sampling), the questionnaire has been used. The questionnaire was anonymous. According to the questionnaire, respondents (blood donors) answered questions:

- Do you know that the medical service carries a risk? (answer YES / NO), 
- What are the risks of a medical service? (you could choose from the following threats - physical, biological, chemical and psychophysical),

- Do you know what abbreviations mean - HIV, HCV, HBV? (there was a place in the questionnaire to explain these abbreviations),

- Have you been informed by an employee who provides a medical service about the risks associated with it? (answer YES / NO),

- Are you aware of preventive measures to avoid the occurrence of a threat during the medical service provided? (answer YES / NO - if yes, please specify).

\section{RESULTS AND DUSCUSSION}

The research has been carried out from June to November 2018. Over 200 questionnaires have been collected, however, after the selection, only 136 of them was complete and became the base of the analysis. Thus, finally in the survey 136 respondents participated. The respondents were blood donors or patients of laboratories where blood is collected. In Figure 1 the characteristics of the respondents in terms of age are shown.

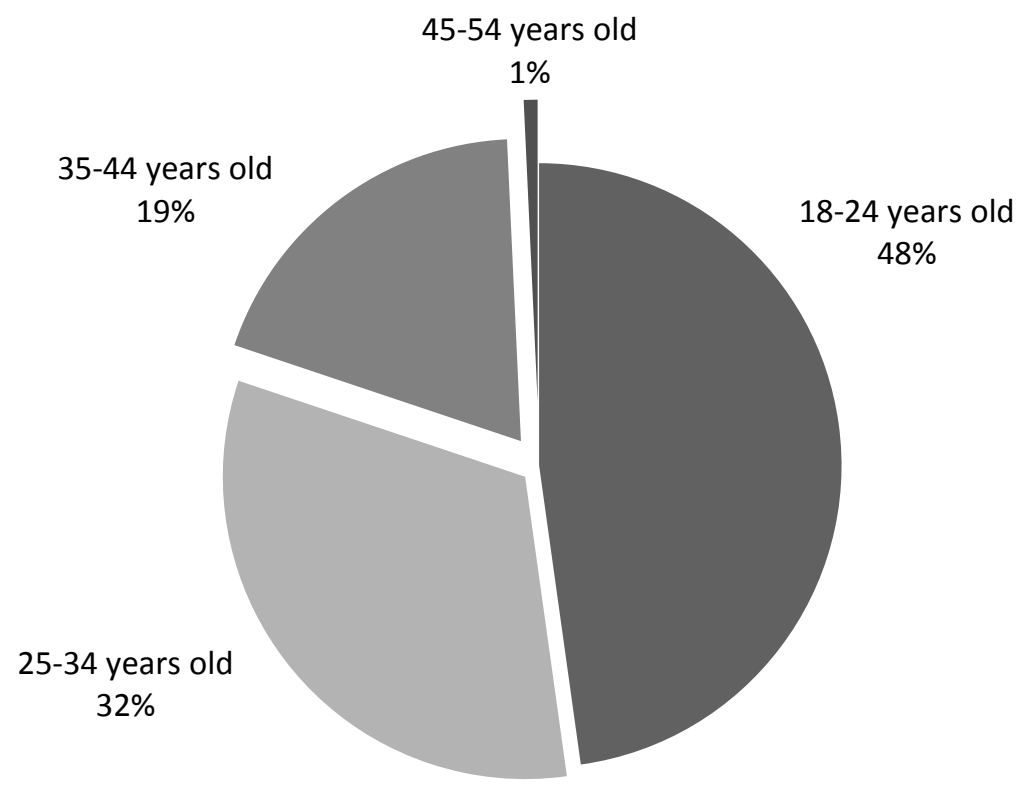

Fig.1. The characteristics of the respondents in terms of age (based on four age groups: 18-24 Source: own study

years old, 25-34 years old, 35-44years old, 45-54years old)

The largest group of respondents were young people aged 18-24 - 48\% of all respondents (65 people). The second most numerous group of respondents are patients aged 25-34 -about 44 people participated in the study (32\% of the total number of respondents). These two groups constituted the vast majority. This may be related to a certain trend prevailing among young people, namely conscious and willing blood donation. In addition, it is a group of people from working age population, who also undergo regular preliminary and periodic medical examinations.

To the question "Do you know that the medical service carries a risk?", about 97 respondents gave answer „yes”. As a threat resulting from the provided medical 
service, only 78 indicated biological as the most important. 23 respondents rated the chemical hazards as the most important. The remaining group of respondents (35 patients) indicated physical hazards as the most important for the provided medical service. In Figure 2 the percentage structure of respondents' answers to the most significant threats was presented.

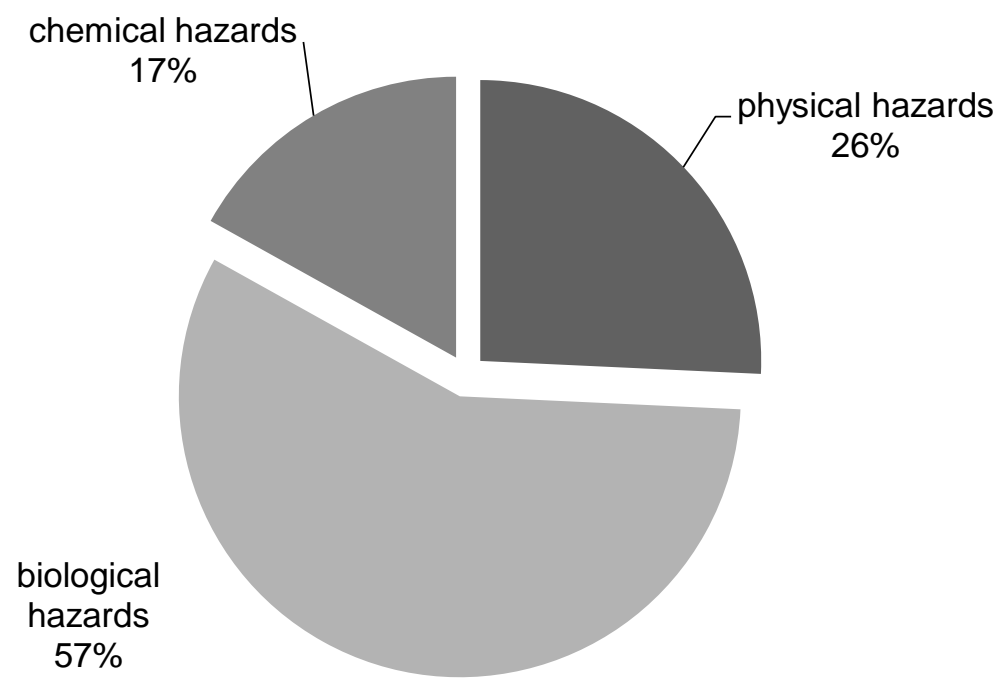

Fig. 2. Percentage structure of the most important threats to the provided medical service in the opinion of respondents(physical hazards, biological hazards, chemical hazards) Source: own study

Subsequently, respondents answered the question "Do you know what abbreviations mean - HIV, HCV, HBV?". None of the patients had a problem to give the full name of the HIV abbreviation, while only 56 respondents correctly entered the meaning of the two abbreviations HCV and HBV.

The next question concerned information received (YES) or not (NIE) by the patient from personnel performing a medical service about the risks associated with its performance. Only 15 patients confirmed that they had received any information about the risks associated with the provided medical service.

The last question, addressed to patients, concerned on preventive actions in the field of medical services provided. The respondents have been asked „Are you aware of preventive measures to avoid the occurrence of a threat during the medical service provided?" Most of the patients answered "yes" (89 people) indicating examples such as disposable syringes, needles, disinfectants and gloves.

\section{CONCLUSIONS}

Threats resulting from the type of provided medical service are varied. Biological hazards are considered the most serious, because their effects determine health and even human life. Blood-borne infections are primarily HIV, HCV and HBV. While the health care professional should be aware or at least have knowledge about how the medical service associated with blood donation may threaten both him and the patient, the patient may not already have such knowledge. Therefore, it is important to 
increase the patient's knowledge and awareness in the discussed issue, first of all through reliable information when providing a medical service. As it appears from the presented preliminary studies, this area of prophylaxis is neglected by healthcare professionals.

\section{REFERENCES}

Abolghasemi, H., Hosseini-Divkalayi, N.S., Seighali, F. 2010. I. Blood donor incentives: a step forward or backward. Asian Journal of Transfusion Science 4(1), 9-13, https://doi.org/ 10.4103/0973-6247.59385.

Aniszewska, M., Pokorska-Śpiewak, M., Kowalik-Mikołajewska, B., Pluta, M., Marczyńska, M. 2019. Hepatitis $C$ infection among pregnant women in central Poland: Significance of epidemiological anamnesis and impact of screening tests to detect infection. Advances in Clinical and Experimental Medicine 28(3). doi: 10.17219/acem/76739.

Eyles E., Manley D., Jones K. 2018. Occupied of classification: Which occupational classification scheme better predicts health outcomes?. Social Science and Medicine, https://doi.org/10.1016/j.socscimed.2018.09.020 (Access 10.11.2018).

Evans, R., Ferguson, E. 2014. Defining and measuring blood donor altruism: a theoreticalapproach from biology, economics and psychology. Vox Sanguinis106, 118-126. https://doi.org/10.1111/vox.12080.

Ingaldi, M., Ulewicz, R. 2018. Evaluation of Quality of the e-Commerce Service. International Journal of Ambient Computing and Intelligence, 9, 2, 55-66.

Irzyniec T., Konodyba-Szymański P. 2010. Identyfikacja zagrożeń oraz ocena ryzyka zawodowego lekarzy medycyny (wyniki wstępne). Journal Ecology and Health, 14, 6, 295-302.

Misje, A.H., Bosnes, V.,Gåsdal, O., Heier, H.E. 2005. Motivation, recruitment and retention of voluntary non-remunerated blood donors: a survey-based questionnaire study. Vox Sanguinis 89 (4), 236-244. https://doi.org/10.1111/j.142 3-0410.2005.00706.x.

Niciejewska, M., Klimecka-Tatar, D. 2018. Health problems among employees in small enterprises as a result of improper OHS management. MATEC Web of Conferences, 183. 01012. https://doi.org/10.1051/matecconf/201818301012.

Pirozzollo J.J., LeMay D.C. 2007. Blood-Borne Infections. Clinics in Sports Medicine, $27,3,425-431$.

Rosak-Szyrocka, J. 2018. Social engineering of human resources and provision of medical services on leadership styles in hospitals. Production Engineering Archives 19, 16-21, https://doi.org/10.30657/pea.2018.19.04.

Twaróg S., Ojrzyńska A. 2018. Usability of spatial analysis for improving the functioning of the blood donation system in Poland. Acta Universitatis Lodziensis. Folia Oeconomica 335 (3), 7-19.

Welch S.B. 2019. Blood borne infections in looked after children. Paediatrics and Child Health, 29, 1, 15-19.

http://www.rynekzdrowia.pl/Uslugi-medyczne/Trzeba-byc-czujnym-by-nie-zarazic-sieHCV,105875,8.html (Access on 10.09.2018). 